\title{
Liver Transplantation in a Child with Kartagener Syndrome: A Case Report
}

\author{
Tumay Uludag Yanaral (D) \\ Pelin Karaaslan' \\ Emine Uzunoglu' \\ Yunus Oktay Atalay' \\ Joseph Drew Tobias (D) ${ }^{2}$ \\ 'Department of Anesthesiology and \\ Reanimation, Faculty of Medicine, \\ Istanbul Medipol University, Istanbul, \\ Turkey; ${ }^{2}$ Departments of Anesthesiology \\ \& Pain Medicine, Nationwide Children's \\ Hospital \& The Ohio State University, \\ Columbus, $\mathrm{OH}$, USA
}

Background: Kartagener syndrome (KS) is a rare genetic disorder consisting of the triad of situs inversus, chronic sinusitis, and bronchiectasis. Although there are previous reports regarding the anaesthetic considerations in KS, none have included liver transplantation.

Case Presentation: An 11-year-old boy with a diagnosis of KS underwent liver transplantation due to extrahepatic biliary atresia. Previous diagnostic imaging confirmed situs inversus and the absence of an inferior vena cava. The patient's peak airway pressure intermittently increased intraoperatively from 15 to $30 \mathrm{~cm} \mathrm{H}_{2} \mathrm{O}$ due to increased pulmonary secretions, which required frequent suctioning of the endotracheal tube. Intraoperative volume resuscitation included $200 \mathrm{~mL}$ of $5 \%$ albumin, 5 units of erythrocyte suspension and 3 units of fresh frozen plasma. Intermittently, a norepinephrine infusion was required to maintain the MAP. Coagulation function was monitoring using the thromboelastogram to guide the use of blood products including fresh frozen plasma. At the end of the surgery, the patient was transferred to the intensive care unit. He was discharged from the intensive care unit on postoperative day 5 , and from the hospital on postoperative day 28 . He continues to do well with normal liver function 23 months after surgery.

Conclusion: Despite the risk of pulmonary related to airway secretions and exacerbation of hemodynamic instability related to anatomical variations in the inferior vena cava anatomy, KS patients can be safely anesthetized with careful planning and attention of the disease process, even for complex surgical procedures such as liver transplantation.

Keywords: anesthesia, child, Kartagener syndrome, liver transplantation, situs inversus

\section{Introduction}

Kartagener syndrome (KS) is a rare autosomal recessive disorder related to defective function and structure of ciliated cells. The disorder affects the function of cilia lining the respiratory tract, fallopian tubes, and spermatozoa as well as the ciliary control of organ positioning during the embryogenic stage. Classically, KS consists of a triad of clinical findings including situs inversus, chronic sinusitis, and bronchiectasis. ${ }^{1}$ Although there are several reports regarding anaesthetic considerations in patients with KS, there are no reports regarding care during liver transplantation in a child. ${ }^{2-4}$ We report a child with KS who underwent a living-related donor liver transplantation and discuss the important perioperative considerations related to KS. Written consent for this publication was obtained from the parent of the patient.

\section{Case Presentation}

Institutional review board approval is not required for publication of case reports at our institution. An 11-year-old boy (27 kg) was referred to our transplantation 
unit for liver transplantation due to extrahepatic biliary atresia. He was diagnosed with $\mathrm{KS}$ at one year of age with situs inversus, growth retardation, central obesity, and a history of a Kasai procedure for biliary atresia. There was no history of anesthetic or surgical complications. His physical examination revealed a young child in no acute distress. Laboratory studies were remarkable for hyperbilirubinemia (total bilirubin: $8.1 \mathrm{mg} / \mathrm{dL}$, direct bilirubin: $6.9 \mathrm{mg} / \mathrm{dL}$ ) and decreased renal function (Blood urea nitrogen: $31 \mathrm{mg} / \mathrm{dL}$, creatinine: $1.7 \mathrm{mg} / \mathrm{dL}$ ). Additional laboratory results included hemoglobin 9.4 $\mathrm{gm} / \mathrm{dL}$, hematocrit $27.2 \%$, platelet $42,000 / \mu \mathrm{L}$, aspartate transaminase $227 \mathrm{U} / \mathrm{L}$, alanine transaminase $143 \mathrm{U} / \mathrm{L}$, prothrombin time 15.1 seconds and activated partial thromboplastin time 29.1 seconds. Pulmonary function tests (spirometry) and arterial blood gas analysis were normal. Previous diagnostic imaging (ultrasonography, chest radiograph, computed tomography, and magnetic resonance imaging) confirmed situs inversus and the absence of the hepatic segment of the inferior vena cava (IVC) with azygos continuation (Figures 1 and 2). Transthoracic echocardiography showed no cardiac abnormalities, with an ejection fraction of $60 \%$. The patient was scheduled for living-related hepatic transplantation from his mother. The mother provided written informed consent for the procedure in accordance with the Declaration of Istanbul. On the day of surgery, the patient was held nil per os for 8 hours and transported to the operating room which had been warmed. Routine American Society of Anesthesiologists' monitors were placed and anaesthesia was induced by the intravenous

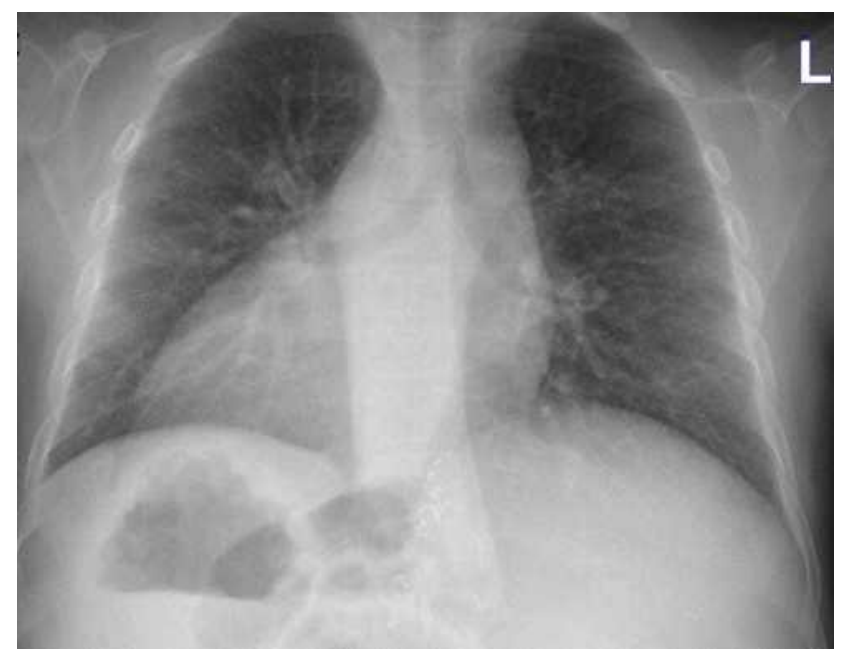

Figure I Preoperative chest radiograph showing dextrocardia and chronic pulmonary changes. administration of thiopental $(6 \mathrm{mg} / \mathrm{kg})$, fentanyl $(2 \mu \mathrm{g} /$ $\mathrm{kg})$, and vecuronium $(0.2 \mathrm{mg} / \mathrm{kg})$. The patient's trachea was intubated easily with a cuffed endotracheal tube (5.5 mm, ID). Controlled mechanical ventilation was initiated with a tidal volume of $7 \mathrm{~mL} / \mathrm{kg}$ at 16 breaths per minute (I:E ratio 1:2), $2 \mathrm{~L} / \mathrm{min}$ fresh gas flow rate, and $5 \mathrm{~cm} \mathrm{H}_{2} \mathrm{O}$ positive end expiratory pressure. Maintenance anesthesia included $2 \%$ sevoflurane in $40 \%$ oxygen and air. This was supplemented with intermittent doses of fentanyl for analgesia and an infusion of vecuronium $(0.05 \mathrm{mg} / \mathrm{kg} / \mathrm{hr})$ to provide neuromuscular blockade. A left radial artery cannula and a left internal jugular vein catheter were placed. The central venous catheter and a left femoral artery cannula were used for pulse contour continuous cardiac output monitoring. Urinary output was also monitored throughout the surgery with a urethral catheter. Normothermia was maintained by using a warming mattress and warming the intravenous fluids. The patient's peak airway pressure intermittently increased intraoperatively from 15 to $30 \mathrm{~cm} \mathrm{H}_{2} \mathrm{O}$ due to increased pulmonary secretions, which required frequent suctioning of the endotracheal tube. Intraoperatively during surgical dissection and accompanying blood loss, hemodynamic instability was noted with the mean arterial pressure (MAP) decreasing to $50 \mathrm{mmHg}$ and tachycardia (heart rate $125-140$ beats/ minute), requiring volume resuscitation. Intraoperative volume resuscitation included $200 \mathrm{~mL}$ of $5 \%$ albumin, 5 units of erythrocyte suspension and 3 units of fresh frozen plasma. Intermittently, a norepinephrine infusion was required to maintain the MAP. Coagulation function was monitoring using the thromboelastogram to guide the use of blood products including fresh frozen plasma. The intraoperative image of the patient during liver transplantation is shown in Figure 3. At the end of the surgery, the patient was transferred to the intensive care unit with the endotracheal tube in place. Sedation and analgesia were provided by continuous infusions of midazolam and fentanyl while his trachea was intubated. His trachea was extubated on postoperative day 1, he was discharged from the intensive care unit on postoperative day 5 , and from the hospital on postoperative day 28 . He continues to do well with normal liver function 23 months after surgery.

\section{Discussion}

Given the comorbid and end-organ involvement related to $\mathrm{KS}$, surgical intervention may be required ranging from 


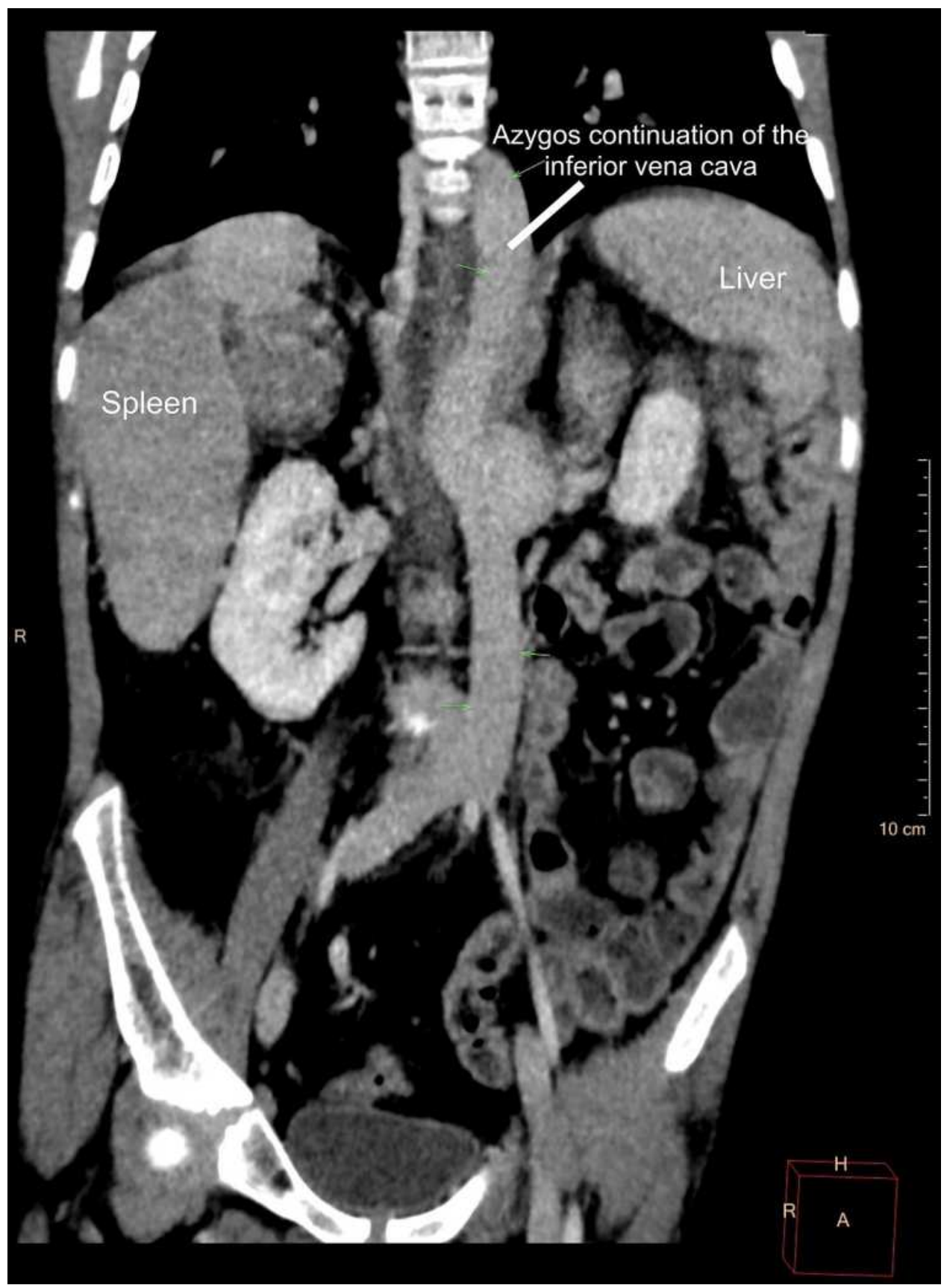

Figure 2 Coronal image of the computed tomography scan demonstrating situs inversus and the absence of the hepatic segment of the inferior vena cava with azygos continuation.

outpatient procedures such as adenotonsillectomy to surgery for chronic bronchiectasis, congenital heart disease, and liver transplantation. While KS classically includes the triad of situs inversus, chronic sinusitis, and bronchiectasis, disorders involving primary ciliary dyskinesia have a myriad of end-organ effects including those related to an impact on embryogenesis and the ongoing clinical effects related to ciliary dysfunction. Disordered embryogenesis can result in situs inversus as well as congenital abnormalities of the heart, lungs, and abdominal organs including the liver.

The most common problems in KS patients are recurrent infections of the sinus and respiratory tract. These respiratory symptoms may appear during the neonatal period, progressing to respiratory insufficiency or failure. ${ }^{5}$ Ciliary dysfunction results in an increased risk of respiratory and sinus infections not only preoperatively, but also in the postoperative period. Chronic pulmonary 


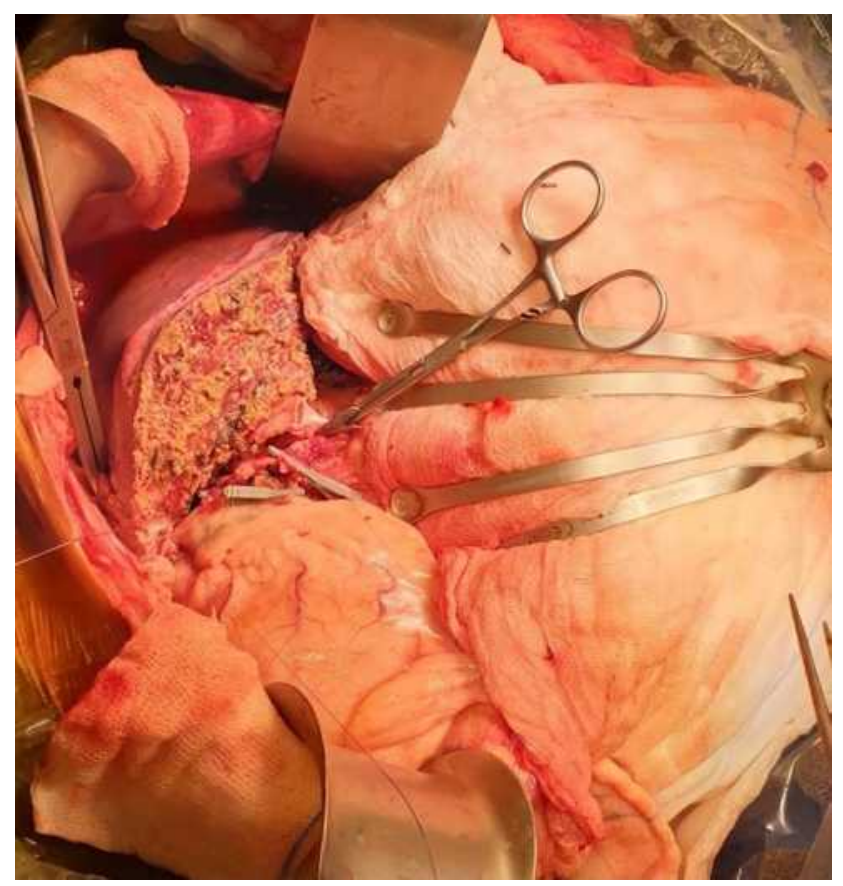

Figure 3 Intraoperative image during liver transplantation. The patient's head is to the left. The liver is seen on the patient's left side.

infections during childhood may progress to bronchiectasis. Pulmonary function testing may demonstrate mild to moderate airway obstruction. ${ }^{6}$ Preoperative evaluation of the extent of pulmonary involvement may include radiology imaging (chest radiograph or computed tomography), simple spirometry, and pulmonary function testing. Preoperative optimization of respiratory function with treatment of infections and use of bronchodilators may be indicated with aggressive pulmonary physiotherapy to avoid postoperative respiratory involvement. Humidification of the inspired gases to provide airway hydration may facilitate intraoperative clearance of airway secretions. As indicated by the surgical procedure, regional anaesthesia may be preferred over general anaesthesia to avoid postoperative respiratory complications. ${ }^{4}$

Anatomic abnormalities related to the impact of defective ciliary function on embryogenesis may include the hepatobiliary, pulmonary, and cardiovascular systems. The cardiac, thoracic, and abdominal anatomies should be determined preoperatively. In the presence of dextrocardia, electrocardiography electrodes, defibrillator paddles and central venous catheterization should be placed on the left side. ${ }^{7}$ Patients with ciliary dysmotility and heterotaxy have an incidence of congenital heart disease up to 200 -fold higher than the general population. $^{7}$
Airway concerns include the potential for tracheobronchial abnormalities that may predispose to mainstem intubation of the left bronchial tree. As chronic sinusitis is one of the triads of KS, nasotracheal intubation may be relatively contraindicated. The diminished or absent mucociliary clearance may result in increased secretions and obstruction of the endotracheal tube. Airway obstruction due to secretions may increase peak airway pressure, as was noted in our patient. Continuous monitoring of pulmonary resistance and compliance (peak airway pressure and exhaled tidal volumes) may provide an early identification of such problems. For the maintenance of general anaesthesia, volatile anesthetic agents may be preferable due to their bronchodilatory effects and rapid elimination, thereby reducing respiratory depression in the early postoperative period. ${ }^{8}$ As neostigmine increases secretions, sugammadex may be preferable for reversing residual neuromuscular blockade. Although sugammadex has not received approval for use on children, it has been shown to effectively reverse neuromuscular blockade in various clinical scenarios in pediatric patients. ${ }^{9}$ Therefore, sugammadex may also be an option in pediatric patients with KS.

Additional perioperative concerns in patients with KS relate to associated hepatic insufficiency/failure which may result in coagulation disturbances, alterations in glucose homeostasis, and derangements in drug metabolism. ${ }^{10,11}$ While primary ciliary dyskinesia-related problems may impact perioperative respiratory function, the presence of situs inversus provides additional challenges regarding surgical technique for hepatic transplantation including anatomical variations in the IVC. Anatomical abnormalities of the IVC may result in additional intraoperative concerns including hemodynamic instability during hepatectomy related to outflow clamping in the recipient. ${ }^{12}$ Perioperative care in patients with KS should address both the anatomical involvement as well as the end-organ effects of the primary disease process.

\section{Abbreviations}

IVC, inferior vena cava; KS, Kartagener syndrome; MAP, mean arterial pressure.

\section{Informed Consent for Publication}

Written consent for publication of the patient's medical details and photographs was obtained from the parent of the patient. The patient's mother donated liver voluntarily with written informed consent, and this was conducted in accordance with the Declaration of Istanbul. The 
Institutional Review Board was informed, and approval was not required for reporting the case.

\section{Acknowledgment}

Appreciation: Dr. Murat Dayangac and Dr. Mehmet Seker for their support through this work.

\section{Funding}

There was no funding received for or related to this work.

\section{Disclosure}

The authors report no conflicts of interest in this work.

\section{References}

1. Boon M, Jorissen M, Proesmans M, De Boeck K. Primary ciliary dyskinesia, an orphan disease. Eur J Pediatr. 2013;172(2):151-162. doi:10.1007/s00431-012-1785-6

2. Mathew PJ, Sadera GS, Sharafuddin S, Pandit B. Anaesthetic considerations in Kartagener's syndrome - a case report. Acta Anaesthesiol Scand. 2004;48(4):518-520. doi:10.1111/j.0001-5172.2004.00357.x

3. Reidy J, Sischy S, Barrow V. Anaesthesia for Kartagener's syndrome. Br J Anaesth. 2000;85(6):919-921. doi:10.1093/bja/85.6.919

4. Kendigelen P, Tütüncü AÇ, Erbabacan ŞE, Kaya G, Altındaş F. Anaesthetic management of a patient with synchronous Kartagener syndrome and biliary atresia. Turk J Anaesthesiol Reanim. 2015;43 (3):205-208. doi:10.5152/TJAR.2015.94546
5. Guo Z, Chen W, Wang L, Qian L. Clinical and genetic spectrum of children with primary ciliary dyskinesia in China. $J$ Pediatr. 2020;225:157-165.e5. doi:10.1016/j.jpeds.2020.05.052

6. Marthin JK, Petersen N, Skovgaard LT, Nielsen KG. Lung function in patients with primary ciliary dyskinesia: a cross-sectional and 3-decade longitudinal study. Am J Respir Crit Care Med. 2010;181 (11):1262-1268. doi:10.1164/rccm.200811-1731OC

7. Kennedy MP, Omran H, Leigh MW, et al. Congenital heart disease and other heterotaxic defects in a large cohort of patients with primary ciliary dyskinesia. Circulation. 2007;115(22):2814-2821. doi:10.1161/CIRCULATIONAHA.106.649038

8. Sahajananda H, Sanjay OP, Thomas J, Daniel B. General anaesthesia for lobectomy in an 8-year-old child with Kartagener's syndrome. Paediatr Anaesth. 2003;13(8):714-717. doi:10.1046/j.14609592.2003.01039.x

9. Tobias JD, Thomas M. Current evidence for the use of sugammadex in children. Paediatr Anaesth. 2017;27(2):118-125. doi:10.1111/ pan. 13050

10. Jacob R. Anaesthesia for biliary atresia and hepatectomy in paediatrics. Indian J Anaesth. 2012;56(5):479-484. doi:10.4103/ 0019-5049.103965

11. Garg R, Goila A, Sood R, Pawar M, Borthakur B. Perioperative anesthetic management of a patient with biliary atresia, situs inversus totalis, and kartegener syndrome for hepatobiliary surgery. J Anaesthesiol Clin Pharmacol. 2011;27(2):256-258. doi:10.4103/ 0970-9185.81837

12. Edgerton CA, Gross M, Kasi N, et al. "Mirror, Mirror on the Wall" ... Pediatric liver transplantation in the case of situs inversus totalis with a disrupted inferior vena cava. Pediatr Transplant. 2018;22(5):e13218. doi:10.1111/petr.13218

\section{Publish your work in this journal}

The International Medical Case Reports Journal is an international, peer-reviewed open-access journal publishing original case reports from all medical specialties. Previously unpublished medical posters are also accepted relating to any area of clinical or preclinical science. Submissions should not normally exceed 2,000 words or 4 published pages including figures, diagrams and references. The manuscript management system is completely online and includes a very quick and fair peer-review system, which is all easy to use. Visit http://www.dovepress.com/testimonials.php to read real quotes from published authors. 